\title{
BMJ Open Investments in cancer research awarded to UK institutions and the global burden of cancer 2000-2013: a systematic analysis
}

\author{
Mahiben Maruthappu, ${ }^{1}$ Michael G Head, ${ }^{2}$ Charlie D Zhou, ${ }^{3}$ Barnabas J Gilbert, ${ }^{4}$ \\ Majd A El-Harasis, ${ }^{5}$ Rosalind Raine, ${ }^{6}$ Joseph R Fitchett, ${ }^{7}$ Rifat Atun ${ }^{7}$
}

To cite: Maruthappu M, Head MG, Zhou CD, et al. Investments in cancer research awarded to UK institutions and the global burden of cancer 2000-2013: a systematic analysis. BMJ Open 2017;7:e013936. doi:10.1136/bmjopen-2016013936

- Prepublication history and additional material is available. To view please visit the journal (http://dx.doi.org/ 10.1136/bmjopen-2016013936).

$\mathrm{MM}$ and $\mathrm{MGH}$ are to be recognised as joint first authors.

Received 18 August 2016 Revised 6 December 2016 Accepted 19 December 2016

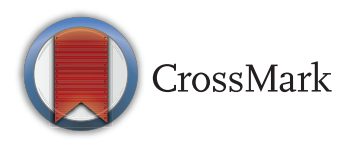

For numbered affiliations see end of article.

Correspondence to

Charlie Zhou;

chazhou@gmail.com

\section{ABSTRACT}

Objectives: To systematically categorise cancer research investment awarded to United Kingdom (UK) institutions in the period 2000-2013 and to estimate research investment relative to disease burden as measured by mortality, disability-adjusted life years (DALYs) and years lived with disability (YLDs).

Design: Systematic analysis of all open-access data.

Setting and participants: Public and philanthropic funding to all UK cancer research institutions, 2000-2013.

Main outcome measures: Number and financial value of cancer research investments reported in 2013 UK pounds (UKE). Mortality, DALYs and YLDs data were acquired from the Global Burden of Disease Study. A compound metric was adapted to estimate research investment relative to disease burden as measured by mortality, DALYS and YLDs.

Results: We identified 4299 funded studies with a total research investment of £2.4 billion. The highest fundings by anatomical sites were haematological, breast, prostate, colorectal and ovarian cancers. Relative to disease burden as determined by a compound metric combining mortality, DALYs and YLDs, gender-specific cancers were found to be highest funded - the five sites that received the most funding were prostate, ovarian, breast, mesothelioma and testicular cancer; the least well-funded sites were liver, thyroid, lung, upper gastrointestinal (GI) and bladder. Preclinical science accounted for $66.2 \%$ of award numbers and $62.2 \%$ of all funding. The top five areas of primary research focus by funding were pathogenesis, drug therapy, diagnostic, screening and monitoring, women's health and immunology. The largest individual funder was the Medical Research Council. In combination, the five lowest funded sitespecific cancers relative to disease burden account for $47.9 \%, 44.3 \%$ and $20.4 \%$ of worldwide cancer mortality, DALYs and YLDs.

Conclusions: Research funding for cancer is not allocated according to relative disease burden. These findings are in line with earlier published studies. Funding agencies and industry should openly document their research investments to improve better targeting of research investment.

\section{Strengths and limitations of this study}

- We systematically analyse UK investment in cancer research and describe trends by cancer site and type of science along the research pipeline.

- We consider cancer research investments alongside the global burden of disease to provide pragmatic commentary about areas of UK research strength and relative neglect to inform funder strategy and contribute towards policy discussions.

- Our study is dependent on the accuracy of original investment data from the funding bodies.

- We could not openly access date of private sector research funding, nor were we able to obtain disaggregated award data from Cancer Research UK, which impedes analysis on the equity and efficiency of investment decisions.

- Disease burden measures are typically an estimate and are subject to the potential introduction of bias; other variables influence funding decisions beyond the burden of disease.

\section{INTRODUCTION}

Cancers account for a high burden of morbidity and mortality worldwide. The Global Burden of Disease (GBD) Study estimates that cancer of all types resulted in 8235700 deaths in 2013. ${ }^{1}$ Predominantly a disease of older age, historically cancer prevalence was high in high-income countries. However, the majority of cancer burden has shifted to low-income countries, which have experienced economic growth with rapid demographic and epidemiological transitions. The number of deaths from cancer are projected to rise due to population growth and aging. ${ }^{23}$ Between 1990 and 2013, the proportion of all deaths that was attributable to cancer rose from $11.9 \%$ to $15.0 \%$, largely among lowincome and middle-income countries and 
site-specific cancers accounted for nine of the 50 leading causes of death, worldwide. ${ }^{1}$

The socioeconomic impact of cancer, in terms of direct costs involved in medical management as well as indirect costs resulting from productivity loss, on patients and caregivers are substantial. Direct health-related costs of cancer have been estimated to incur $€ 51.0$ billion within in the European Union ${ }^{4}$ and $\$ 124.5$ billion in the United States of America (USA). ${ }^{5}$ Indirect costs are estimated to account for additional losses of $€ 75.2$ billion and $\$ 115.8$ billion, respectively. Economic evaluation of the impact of cancer outside of these two geographical regions has been lacking.

Investment in research and development (R\&D) for cancers produces global public benefits that have a positive effect locally and worldwide, irrespective of the site of the work or the location of the institution receiving an award, bringing substantial health, social and economic benefit.

There are several national and international funding bodies that make cancer research investments along the R\&D pipeline, from preclinical studies through to clinical trials and applied research. The United Kingdom (UK) is one of the world's leading investors and producers of global biomedical and health research. Previous analyses by the Research Investments in Global Health study (ResIn, http://www.researchinvestments.org) have systematically analysed public and philanthropic awards totalling £3.7 billion to UK institutions for infectious disease from 1997 to 2013, and evaluated funding against global disease burden ${ }^{6} 7$ and publications and citations as a marker of research output. ${ }^{8}$ Tracking investments in $\mathrm{R} \& \mathrm{D}$ provides information and evidence to inform funding decisions and priority setting. Here, we present a systematic analysis of cancer-related research awarded by public and philanthropic funders to UK institutions from 2000 to 2013, categorise the data against a range of cancer-specific and cross-cutting disease areas and assess the award data against global measures of mortality, disability-adjusted life years (DALYs) and years lived with disability (YLD) across three time points and in the wider literature.

\section{METHODS}

Our methods build on those developed for the infectious disease research investment analysis, which are described in detail elsewhere ${ }^{67}$ and adapted in subsequent peer-reviewed publications (http://www. researchinvestments.org/publications).

We systematically examined funding awards from a number of public and philanthropic funding bodies (including the Medical Research Council (MRC), Department of Health, Biotechnology and Biological Sciences Research Council, Engineering and Physical Science Research Council, Wellcome Trust, European Commission as well as nine members of the Association of Medical Research Charities) between 2000 and 2013.
Information was obtained by downloading openly accessible information on the funder website, contacting the funder to request the information or searching existing funding databases. For each award, the title and abstract, where available, were individually screened for relevance to cancer research. We excluded awards that were (1) not obviously or immediately relevant to oncology; (2) led by a non-UK institution and (3) not considered to be for R\&D activity. Studies that were completed without funding were also excluded. Private sector data were not available to evaluate at the same level of detail as public and philanthropic research award data, and were therefore excluded from this analysis.

Cancer Research UK (CRUK) would not provide their funding data at individual award level and so could not be included in the main analysis. There is some description of individual CRUK awards without grant amounts available at https://europepmc.org/. We report total number of studies in this analysis.

Where awards were described in currencies other than UK pounds, these were converted to UK pounds using the mean exchange rate in the year of the award. All included awards were adjusted for inflation and reported in 2013 UK pounds.

Each study in the data set was reviewed by one author (either CDZ, GJG, MAE-H or MGH) and assigned to as many of 14 cross-cutting categories as appropriate. The 14 association categories were paediatric, geriatric, infection-associated, women's health, men's health, occupational health, pathogenesis, diagnostic/screening/monitoring, drug therapy, radiotherapy, surgery, immunology, psychosocial and global health. Awards were defined as global health if they were considered to pursue a clear non-UK focus (eg, 'thyroid cancer in Kenya'). The other category was only used when none of the aforementioned categories were deemed to be appropriate. Studies were also allocated to one of five categories along the R\&D pipeline: preclinical; phase I, II or III clinical trials; product development (including phase IV activity); public health and cross-disciplinary research. The cross-disciplinary category was defined as an award containing significant components across two distinct areas along the R\&D pipeline (such as preclinical research leading directly into a phase I trial). Provisional datasets were circulated to all authors for review and comment with checks by second authors on sections of the data and any disagreements settled by consensus. Final datasets were then again circulated for further review by all authors. Microsoft Excel 2010 and 2013 and Stata (V13) softwares were used for data analysis.

Global data on mortality, DALYs and YLDs were available at time points 2005, 2010 and 2013. All burden data were sourced from the findings of the GBD study, for $2013^{1910}$ and for 2010. ${ }^{11}{ }^{12}$ Burden data from 2005 were obtained directly from colleagues at the Institute for Health Metrics and Evaluation, USA. As defined by the GBD study, YLDs for a disease or injury are the sum 
of the YLDs for each sequela associated with the disease or injury. ${ }^{10}$ DALYS are the sum of years of life lost (YLLs) and YLDs for each age-sex-country group. ${ }^{9}$

In order to allow direct comparison of relative investment with global health metrics across disease areas and between different time periods, metrics were adapted from the infectious disease analyses to estimate the 'investment per mortality/DALY/YLD observed"'. The metrics were created using the following equation -

\section{(Total research investment up to the year before}

the time point/number of deaths, DALYs or YLD

at time point)/number of years of investment included.

For example, for assessment of breast cancer mortality at the 2013 time point, we took the sum of breast cancer research investment 2000-2012 (£124305 716) and divided that by number of deaths reported in 2013 (471 000), and divided the result by the number of years of investment included (13) to get an 'investment per mortality observed' metric of $£ 20.30$.

These metrics were applied for research relating to 16 site-specific cancers, where there was comparable data in the ResIn and GBD studies. We defined lung cancer by aggregating 'tracheal, bronchus and lung cancer' burden data from the GBD study. Similarly, we defined skin cancer by aggregating 'malignant skin melanoma' and 'non-malignant skin cancer', and we defined upper gastrointestinal (GI) cancer by aggregating 'oesophageal' and 'stomach cancer'. The use of total investment and the division by number of years included aimed to reduce the impact of the volatility of annual research funding and the relatively short periods between time points. Ranking scores of the investment metrics were developed for the 16 sites of cancer against 2013 burdens. Cancers were ranked in order of relative investment against burden from high to low and assigned a score (from 1 to 16). The mean ranking scores across mortality, DALYs and YLDs were used to illustrate an overall relative level of investment against 2013 global disease burden.

\section{Patient involvement}

There was no patient involvement in this study.

\section{RESULTS}

We identified 4299 funded studies that met our inclusion criteria (table 1). The funding for these studies represented a total research investment of almost £2.4 billion. The mean award amount for each study was $£ 555513$ (SD £1 429510) and median was £231 559 (IQR £114 619-487 063). A total of 2416 awards (56.2\% of total) were designated towards a named site-specific cancer (table 1), equating to £1.0 billion (40.3\% of total). The top five cancer sites in terms of award number were haematological, breast, colorectal, prostate and skin; the bottom five were testicular, bone, bladder, thyroid and cholangiocarcinoma (table 1). The top five cancer sites in terms of total funding were haematological, breast, prostate, colorectal and ovarian; the bottom five were testicular, mesothelioma, thyroid, bladder and cholangiocarinoma. Mean funding per award varied greatly between sites with prostate cancer receiving the most ( $£ 1.47$ million) and bladder cancer the least (£117 385).

The top five areas of primary research focus, by number of awards, were drug therapy, diagnostic, screening and monitoring, women's health, immunology and pathogenesis; the bottom five areas were men's health, surgery, occupational health, global health and geriatrics (table 2). In terms of net funding, the top five areas of research were pathogenesis, drug therapy, diagnostic, screening and monitoring and women's health and immunology; the bottom five were surgery, psychosocial, global health, occupational health and geriatrics.

The majority of awards were focused on preclinical science, accounting for $66.2 \%$ of award numbers and $62.2 \%$ of all funding (table 3). In terms of award number, this was followed by public health, crossdisciplinary, phase I-III and product development. This order was reflected in terms of net investment, although cross-disciplinary studies ranked ahead of public health studies. Phase I-III clinical trials received the highest mean funding per award, at £736 172 (SD £3 361 312), while public health research received the least, at $£ 496744$ (SD £1 000 757).

The largest individual funder of cancer research of the studies identified was the MRC, accounting for $35.1 \%$ of all funding (table 4). The charitable sector was responsible for $39.5 \%$ of all awards (excluding CRUK) but $17.4 \%$ of funding. The European Commission was responsible for the largest mean grant per award (£1.58 million).

We generated a compound ranking score for the 16 sites of cancer against 2013 global disease burdens, across mortality, DALYs and YLDs (table 5). The amount of investment per unit disease burden (£ per death/ DALY/YLD) was used to compile this compound ranking score. The data for all site-specific cancers measured here are presented in the online supplementary information (see online supplementary tables S1-S3 and figures S1-S3). We identified the five sites that received the most funding relative to disease burden as prostate, ovarian, breast, mesothelioma and testicular cancer. The least well-funded sites relative to disease burden were cancers of the liver, thyroid, lung, upper GI and bladder.

We were able to obtain some disaggregated data for 3284 CRUK research grants during the period of interest but this excluded individual award data. Compared with the aggregation of all other funders, CRUK placed more of a focus on funding towards cancers of the prostate, ovary and liver-by study number these sites accounted for $6.9 \%, 3.4 \%$ and $2.7 \%$ of CRUK-funded studies compared with 2.1, 1.1 and $0.9 \%$ of all studies in our quantitative database, respectively. CRUK preferentially funded 
Table 1 Cancer research investment awards and funding by site. All investment reported in 2013 UK pounds

\begin{tabular}{|c|c|c|c|c|c|c|c|c|}
\hline \multirow[b]{2}{*}{ Site of cancer } & \multicolumn{6}{|c|}{ All funders where investment data were available } & \multicolumn{2}{|c|}{ Cancer Research UK } \\
\hline & $\begin{array}{l}\text { Number of } \\
\text { awards }\end{array}$ & $\begin{array}{l}\text { Percentage } \\
\text { of total }\end{array}$ & $\begin{array}{l}\text { Sum } \\
\text { investment }(£)\end{array}$ & $\begin{array}{l}\text { Percentage } \\
\text { of total }\end{array}$ & Mean award, $£(S D)$ & Median award, $£$ (IQR) & $\begin{array}{l}\text { Number of } \\
\text { awards }\end{array}$ & $\begin{array}{l}\text { Percentage of } \\
\text { all oncology } \\
\text { research awards }\end{array}$ \\
\hline Breast & 571 & $13.3 \%$ & $£ 137960107$ & $5.8 \%$ & $241611(414584)$ & $135752(25000-216673)$ & 273 & $8.3 \%$ \\
\hline Haematological & 1158 & $26.9 \%$ & $£ 381008394$ & $16.0 \%$ & $329022(476943)$ & $186813(120437-272324)$ & 225 & $6.9 \%$ \\
\hline Colorectal & 147 & $3.4 \%$ & $£ 77279857$ & $3.2 \%$ & $525713(674881)$ & 251800 (102 078-819 866) & 205 & $6.2 \%$ \\
\hline Prostate & 92 & $2.1 \%$ & $£ 135290779$ & $5.7 \%$ & 1470552 (6 156372$)$ & 333757 (155 227-721 037) & 123 & $3.7 \%$ \\
\hline Ovarian & 48 & $1.1 \%$ & $£ 44709938$ & $1.9 \%$ & 931457 (3 380145$)$ & 226764 (131 990-627 401) & 112 & $3.4 \%$ \\
\hline Lung & 82 & $1.9 \%$ & $£ 24263280$ & $1.0 \%$ & 295893 (556 278) & $146123(66701-242934)$ & 89 & $2.7 \%$ \\
\hline Skin & 87 & $2.0 \%$ & $£ 22179011$ & $0.9 \%$ & 254931 (453 726) & 85406 (69 629-248 603) & 84 & $2.6 \%$ \\
\hline Brain & 22 & $0.5 \%$ & $£ 9994255$ & $0.4 \%$ & 454284 (498 933) & 401046 (196 928-528 008) & 83 & $2.5 \%$ \\
\hline Upper GI & 18 & $0.4 \%$ & $£ 19094230$ & $0.8 \%$ & 1060791 (1 448010$)$ & 788850 (80 964-1 296 962) & 80 & $2.4 \%$ \\
\hline Head and neck & 20 & $0.5 \%$ & $£ 18250632$ & $0.8 \%$ & 912531 (1 003091$)$ & $389751(167358-1602465)$ & 68 & $2.1 \%$ \\
\hline Renal & 19 & $0.4 \%$ & $£ 13885496$ & $0.6 \%$ & 730815 (678 732) & 479197 (244 075-1 252 574) & 48 & $1.5 \%$ \\
\hline Bladder & 10 & $0.2 \%$ & $£ 1173856$ & $0.0 \%$ & 117385 (106 902) & $94520(29264-173855)$ & 48 & $1.5 \%$ \\
\hline Cervical & 26 & $0.6 \%$ & $£ 14328402$ & $0.6 \%$ & 551092 (877 250) & 210179 (88 934-368 402) & 43 & $1.3 \%$ \\
\hline Pancreatic & 16 & $0.4 \%$ & $£ 9453577$ & $0.4 \%$ & $590848(519850)$ & 276237 (191 804-1 033948$)$ & 40 & $1.2 \%$ \\
\hline Bone & 13 & $0.3 \%$ & $£ 17242183$ & $0.7 \%$ & 1326322 (1 604685$)$ & 685853 (243 559-1999 907) & 29 & $0.9 \%$ \\
\hline Liver & 37 & $0.9 \%$ & $£ 25037541$ & $1.0 \%$ & $676690(847$ 151) & 319082 (177 974-776 480) & 20 & $0.6 \%$ \\
\hline Mesothelioma & 30 & $0.7 \%$ & $£ 4476088$ & $0.2 \%$ & 149202 (101 201) & $137103(95895-205500)$ & 11 & $0.3 \%$ \\
\hline Cholangiocarcinoma & 2 & $0.0 \%$ & $£ 582405$ & $0.0 \%$ & $\mathrm{n} / \mathrm{a}$ & $\mathrm{n} / \mathrm{a}$ & 11 & $0.3 \%$ \\
\hline Testicular & 14 & $0.3 \%$ & $£ 5949990$ & $0.2 \%$ & 424999 (507 277) & 242175 (102 938-411 010) & 11 & $0.3 \%$ \\
\hline Thyroid & 4 & $0.1 \%$ & $£ 1375881$ & $0.1 \%$ & $\mathrm{n} / \mathrm{a}$ & $\mathrm{n} / \mathrm{a}$ & 7 & $0.2 \%$ \\
\hline Total & 4299 & & $£ 2388152318$ & & $555513(1429510)$ & 231559 (114 619-487 063) & 3284 & \\
\hline
\end{tabular}

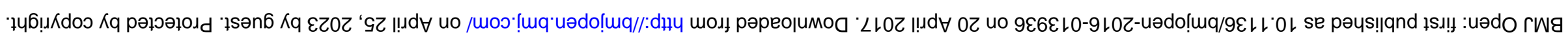




\begin{tabular}{|c|c|c|c|c|c|c|c|c|}
\hline \multirow[b]{2}{*}{$\begin{array}{l}\text { Cross-cutting } \\
\text { theme }\end{array}$} & \multicolumn{6}{|c|}{ All funders where investment data were available } & \multicolumn{2}{|c|}{ Cancer Research UK } \\
\hline & $\begin{array}{l}\text { Number of } \\
\text { awards }\end{array}$ & $\begin{array}{l}\text { Percentage } \\
\text { of total }\end{array}$ & $\begin{array}{l}\text { Sum } \\
\text { investment }(£)\end{array}$ & $\begin{array}{l}\text { Percentage } \\
\text { of total }\end{array}$ & Mean award, $£$ (SD) & Median award, £ (IQR) & $\begin{array}{l}\text { Number of } \\
\text { awards }\end{array}$ & $\begin{array}{l}\text { Percentage } \\
\text { of all oncology } \\
\text { research awards }\end{array}$ \\
\hline $\begin{array}{l}\text { Pathogenesis } \\
\text { (mechanism) }\end{array}$ & 227 & $5.3 \%$ & $£ 1374387838$ & $57.6 \%$ & 543881 (955 710) & 248573 (135 752-506 232) & 1674 & $51.0 \%$ \\
\hline Drug therapy & 1104 & $25.7 \%$ & $£ 620961060$ & $26.0 \%$ & 562464 (1 910050$)$ & 202342 (105 622-436 559) & 935 & $28.5 \%$ \\
\hline $\begin{array}{l}\text { Diagnostic, } \\
\text { screening and } \\
\text { monitoring }\end{array}$ & 681 & $15.8 \%$ & $£ 359618823$ & $15.1 \%$ & $528074(1155156)$ & 205728 (102 672-513 836) & 404 & $12.3 \%$ \\
\hline Women's health & 640 & $14.9 \%$ & $£ 199534693$ & $8.4 \%$ & $311773(1041520)$ & 153845 (56 515-227 202) & 287 & $8.7 \%$ \\
\hline $\begin{array}{l}\text { Immunology } \\
\text { (biologics) }\end{array}$ & 451 & $10.5 \%$ & $£ 194086617$ & $8.1 \%$ & 430347 (760 955) & 240052 (125 669-466 250) & 212 & $6.5 \%$ \\
\hline Radiotherapy & 112 & $2.6 \%$ & $£ 88262353$ & $3.7 \%$ & 788056 (2 413445$)$ & 243333 (106 175-439 419) & 209 & $6.4 \%$ \\
\hline Psychosocial & 117 & $2.7 \%$ & $£ 23445835$ & $1.0 \%$ & 200391 (352 410) & 87463 (27 317-239 059) & 122 & $3.7 \%$ \\
\hline Men's health & 111 & $2.6 \%$ & $£ 143392908$ & $6.0 \%$ & 1291828 (5 617 919) & 285203 (126 037-700 353) & 120 & $3.7 \%$ \\
\hline Paediatrics & 175 & $4.1 \%$ & $£ 62641938$ & $2.6 \%$ & $357953(547484)$ & 183099 (89 522-322 261) & 118 & $3.6 \%$ \\
\hline Surgery & 72 & $1.7 \%$ & $£ 37900334$ & $1.6 \%$ & 526393 (684 908) & 235413 (97 890-761 651) & 95 & $2.9 \%$ \\
\hline Infection associated & 129 & $3.0 \%$ & $£ 56819379$ & $2.4 \%$ & 440460 (798 013) & 231836 (134 693-439 378) & 48 & $1.5 \%$ \\
\hline Global health & 12 & $0.3 \%$ & $£ 6434960$ & $0.3 \%$ & 536246 (1 089 118) & 129738 (77 519-459 274) & 12 & $0.4 \%$ \\
\hline Geriatrics & 7 & $0.2 \%$ & $£ 1616394$ & $0.1 \%$ & 230913 (254 925) & 121623 (76 421-262 167) & 8 & $0.2 \%$ \\
\hline Occupational health & 18 & $0.4 \%$ & $£ 2576841$ & $0.1 \%$ & 143157 (116 928) & 137103 (33 857-199 998) & 8 & $0.2 \%$ \\
\hline Total & 4299 & & $£ 2388152318$ & & 555513 (1 429510$)$ & 231559 (114 619-487 063) & 3284 & \\
\hline
\end{tabular}


Table 3 Cancer research investment awards and funding by type of science

\begin{tabular}{|c|c|c|c|c|c|c|c|c|}
\hline \multirow[b]{2}{*}{ Type of science } & \multicolumn{6}{|c|}{ All funders where investment data were available } & \multicolumn{2}{|c|}{ Cancer Research UK } \\
\hline & $\begin{array}{l}\text { Number of } \\
\text { awards }\end{array}$ & $\begin{array}{l}\text { Percentage } \\
\text { of total }\end{array}$ & $\begin{array}{l}\text { Sum } \\
\text { investment }(£)\end{array}$ & $\begin{array}{l}\text { Percentage } \\
\text { of total }\end{array}$ & Mean award, $£$ (SD) & Median award, £ (IQR) & $\begin{array}{l}\text { Number of } \\
\text { awards }\end{array}$ & $\begin{array}{l}\text { Percentage of } \\
\text { all oncology } \\
\text { research awards }\end{array}$ \\
\hline Preclinical & 2845 & $66.2 \%$ & $£ 1485997379$ & $62.2 \%$ & $522318(1006$ 600) & 240974 (132 188-490 872) & 1809 & $55.1 \%$ \\
\hline Phase I-III & 303 & $7.0 \%$ & $£ 223060276$ & $9.3 \%$ & 736172 (3 361312$)$ & 178535 (70 934-502 399) & 647 & $19.7 \%$ \\
\hline Product development & 172 & $4.0 \%$ & $£ 104214364$ & $4.4 \%$ & 605897 (2 213394$)$ & 193051 (75 270-360 813) & 52 & $1.6 \%$ \\
\hline Cross-disciplinary & 441 & $10.3 \%$ & $£ 315145351$ & $13.2 \%$ & 714615 (1586 882) & 238523 (126 589-703 764) & 328 & $10.0 \%$ \\
\hline Public health & 512 & $11.9 \%$ & $£ 254333282$ & $10.6 \%$ & $496744(1000757)$ & 209364 (82 870-383 623) & 443 & $13.5 \%$ \\
\hline Unable to specify & 26 & $0.6 \%$ & $£ 5401666$ & $0.2 \%$ & $n / a$ & $\mathrm{n} / \mathrm{a}$ & 5 & $0.2 \%$ \\
\hline Total & 4299 & & $£ 2388152318$ & & 555513 (1 429510$)$ & 231559 (114 619-487 063) & 3284 & \\
\hline
\end{tabular}

All investment reported in 2013 UK pounds.

Table 4 Cancer research investment awards and funding by funding agency (excluding CRUK)

\begin{tabular}{|c|c|c|c|c|c|c|}
\hline \multirow[b]{2}{*}{ Funder } & \multicolumn{6}{|c|}{ All funders where investment data were available } \\
\hline & $\begin{array}{l}\text { Number of } \\
\text { awards }\end{array}$ & $\begin{array}{l}\text { Percentage } \\
\text { of total }\end{array}$ & Sum investment $(£)$ & $\begin{array}{l}\text { Percentage } \\
\text { of total }\end{array}$ & Mean award, $£(S D)$ & Median award, $£$ (IQR) \\
\hline MRC & 768 & $17.9 \%$ & $£ 837649875$ & $35.1 \%$ & $1090690(1770533)$ & 504606 (305 375-1 153 374) \\
\hline Charity (excluding Wellcome and CRUK) & 1699 & $39.5 \%$ & $£ 415189093$ & $17.4 \%$ & 244372 (391 813) & $151912(81000-223244)$ \\
\hline Department of Health & 586 & $13.6 \%$ & $£ 413421823$ & $17.3 \%$ & 705498 (2 675 223) & 232173 (102 391-471 236) \\
\hline BBSRC & 511 & $11.9 \%$ & $£ 223651002$ & $9.4 \%$ & $437673(388793)$ & 373356 (267 848-501 592) \\
\hline EPSRC & 356 & $8.3 \%$ & $£ 201861623$ & $8.5 \%$ & 567027 (972 696) & 306906 (144 056-604 016) \\
\hline Wellcome & 193 & $4.5 \%$ & $£ 140425805$ & $5.9 \%$ & 727594 (1 679370$)$ & 226761 (164 547-427 455) \\
\hline European Commission (ERC) & 50 & $1.2 \%$ & $£ 78757447$ & $3.3 \%$ & $1575149(731858)$ & 1409678 (1 252 574-1 830017$)$ \\
\hline Other & 136 & $3.2 \%$ & $£ 77195650$ & $3.2 \%$ & 567615 (1901 202) & 129944 (69 309-263 613) \\
\hline Total & 4299 & & $£ 2388152318$ & & $555513(1429510)$ & 231559 (114 619-487 063) \\
\hline
\end{tabular}

All investment reported in 2013 UK pounds.

BBSRC, Biotechnology and Biological Sciences Research Council; CRUK, Cancer Research UK; EPSRC, Engineering and Physical Science Research Council; ERC, European Research Council; MRC, Medical Research Council. 
Table 5 Compound ranking score for cancer research investment against 2013 global disease burdens, across mortality, years lived with disability (YLDs) and disability-adjusted life years (DALYs), by cancer site

\begin{tabular}{|c|c|c|c|c|}
\hline \multirow[b]{2}{*}{ Disease } & \multicolumn{4}{|c|}{ Research investment (UK pound) by burden observed, 2013} \\
\hline & $\begin{array}{l}\text { Mean ranking across } \\
\text { all burden metrics }\end{array}$ & Mortality & $\begin{array}{l}\text { Years lived with } \\
\text { disability }\end{array}$ & $\begin{array}{l}\text { Disability-adjusted } \\
\text { life years }\end{array}$ \\
\hline Prostate & 2.7 & 2 & 4 & 2 \\
\hline Ovarian & 3.0 & 4 & 2 & 3 \\
\hline Mesothelioma & 4.0 & 6 & 1 & 5 \\
\hline Breast & 4.0 & 3 & 5 & 4 \\
\hline Testicular & 4.7 & 1 & 3 & 10 \\
\hline Skin & 5.0 & 5 & 9 & 1 \\
\hline Colorectal & 6.7 & 7 & 7 & 6 \\
\hline Renal & 8.3 & 8 & 10 & 7 \\
\hline Cervical & 9.7 & 9 & 12 & 8 \\
\hline Pancreatic & 10.0 & 12 & 6 & 12 \\
\hline Brain & 11.0 & 11 & 11 & 11 \\
\hline Thyroid & 11.3 & 10 & 15 & 9 \\
\hline Liver & 11.3 & 13 & 8 & 13 \\
\hline Lung & 13.7 & 14 & 13 & 14 \\
\hline Upper GI & 14.7 & 15 & 14 & 15 \\
\hline Bladder & 16.0 & 16 & 16 & 16 \\
\hline
\end{tabular}

research investigating pathogenesis, which accounted for $51.0 \%$ of all grants awarded. In comparison, only $5.3 \%$ of all awards in our quantitative database were identified as primarily focused on pathogenesis.

\section{DISCUSSION}

We identified 4299 funded studies, with a total research investment of $£ 2.4$ billion. We performed qualitative analysis on a further 3284 CRUK-funded awards. The vast majority of all awards awarded were investigating at least one of pathogenesis, diagnosis, monitoring and screening and drug therapy. In the absence of CRUK data, the MRC and the Department of Health were the two leading funding sources. Preclinical research accounted for $£ 1.5$ billion $(62.2 \%)$ of total R\&D investment. Four of the five highest funded cancer sites relative to global disease burden were gender specific-namely prostate, ovarian, breast and testicular cancers. Cancer research with a clear focus on women's health accounted for 640 studies $(14.9 \%)$ and $£ 199.5$ million $(8.4 \%)$ of investment. In comparison, 111 studies (2.6\%) and £143.3 million $(6.0 \%)$ of investment had a clear link with men's health. This may reflect the successes of various institutions and charities that have sought to increase awareness of these sex-specific cancers. Breast cancer, the most commonly diagnosed cancer in the UK and the leading cause of cancer death in women, and prostate cancer, the second most frequently diagnosed cancer and the sixth leading cause of cancer death among men, were found to be relatively well funded. ${ }^{12}$

We highlight several cancer sites where there might be underinvestment, namely that of liver, thyroid, lung, upper GI tract and bladder. In our analysis, cancer of the upper GI tract combines oesophageal and stomach cancer. These site-specific cancers identified to be relatively underfunded account for a substantial proportion of global cancer burden. Globally, these sites account for $47.9,44.3$ and $20.4 \%$ of the global mortality, ${ }^{1}$ DALYs ${ }^{9}$ and YLDs ${ }^{10}$ of all cancers, respectively. The disparity between YLDs and DALYs demonstrates the poor prognosis and high mortality of these particular sites when compared against all neoplastic diseases. Lung, liver, stomach and oesophagus are the first, second, third and fifth, leading sites of neoplastic mortality worldwide. ${ }^{1}$

Two previous studies have compared UK cancer funding with YLLs. Burnet et $a l^{13}$ reported the relative overfunding of breast cancers and leukaemia. Carter et $a l^{1415}$ likewise reported higher levels of funding than their burden suggests of testicular, leukaemia, Hodgkin's lymphoma, breast, cervical, ovarian and prostate cancer with relative underfunding of gallbladder, lung, nasopharyngeal, intestine, stomach, pancreatic, thyroid, oesophageal, liver, kidney, bladder and brain/central nervous system (CNS). Furthermore, they show that these broad discrepancies between cancer burden and research investment are also reflected in the data from the USA. Over the past decade in the UK, there has generally been a transition of increased funding towards previously underfunded cancers with one notable exception being breast cancer. Although our site-specific classifications differed slightly, our findings are broadly consistent with these previous studies with the identification of haematological and sex-specific cancers being relatively well funded. We are unable to account exactly for the slight differences in our findings (such as cervical and colorectal cancers); however, they are likely due to our metrics which seek to capture mortality 
(global mortality and DALYs) and life burden (DALYs and YLDs) rather than just mortality, and also different included components in the respective datasets.

With regard to interventions research, there is heavy investment in drug-based modalities. A total of $£ 620.9$ million $(26.0 \%)$ was invested in novel drug therapies and $£ 194.1$ million $(8.1 \%)$ was invested in the emergent role of immunomodulation. In comparison, funding towards radiotherapy and surgical interventions accounted for $£ 88.2$ million (3.7\%) and $£ 37.9$ million $(1.6 \%)$, respectively. In high-income settings, around half of new cancer diagnoses will undergo a course of radiotherapy treatment during their clinical management; roughly, a quarter will receive two or more courses. ${ }^{16}{ }^{17}$ Globally, over $80 \%$ of cancer cases will warrant surgical intervention, where it has preventative, diagnostic, curative, supportive, palliative and reconstructive roles. ${ }^{18}$

Analysis by R\&D pipeline showed that research investment in the UK places a heavy emphasis on preclinical research, but relatively little investment towards phase I-III clinical trials or product development, and this is in line with previous research in infectious disease investment. ${ }^{6}$ This may reflect the strengths of UK institutions in preclinical science, and could suggest a need to strengthen research capacity further down the R\&D chain. It would be useful to determine whether investment reflects the priorities of funding agencies and whether this is comparable with research investment in other countries. We noted a lack of readily available data from the pharmaceutical industry and this is likely to leave a data gap in particular for sum totals of investment in clinical trials of pharmaceutical products.

Our findings contribute to the development of transparent and objective methods to couple the allocation of limited research funds with disease burden. Previous studies have suggested that financial investment might appropriately be coupled with DALYs as a measure of burden. ${ }^{19-22}$ Furthermore, previous UK research suggests that publicly funded research offers substantial rates of return in terms of health and monetary benefit in the case of cancer specifically ${ }^{23}$ and biomedical sciences as a whole. ${ }^{25}$ We have further sought to incorporate mortality rates and YLDs into the consideration of cancer research investment. These analyses, when considered together, provide convincing pragmatic evidence of UK research strength and types of cancer where research investment has been particularly lacking.

We have chosen to compare cancer research funding with global rather than domestic UK disease burden. Owing to increasing globalisation, the emergence of non-communicable disease burden in resource-poor settings, the internationalisation of healthcare, the flow of people across national borders and the role of the UK as an international centre of biomedical research, we believe this approach to be justified.

However, defining an appropriate amount of research investment for each site-specific cancer is challenging since cancers of similar disease burdens may warrant different levels of investment to develop cost-effective interventions. Decisions may be influenced by any of a number of factors, for example, due to exceptional need, as may be the case in mesothelioma, or due to public awareness and third-party lobbying, as may be the case with regards to the gender-specific cancers.

A variety of factors contribute towards the difficulty in tracking net cancer research investment within the UK. Fragmentation of data from a large number of diverse public and private sources of funding, poorly designed donor accounting structures and the paucity of disaggregated information from the private sector limit the quality of the evidence base and thus the ability to inform policy in real time. In our study, we were unable to obtain disaggregated investment data from CRUK, despite requests across 2014 and 2015. It is noteworthy however that CRUK representatives are welcoming and encouraging the expansion of data-sharing and promoting the availability, accessibility and discoverability of such data 26, 27. In our experience across the ResIn infection and cancer analysis, more than 200 high profile research funder in the UK and the USA have been supportive of lending transparency to their investment profiles. The lack of data liberation across noncommunicable diseases impedes open scrutiny and hinders timely and effective response to this growing global disease burden. ${ }^{28} 29$ Transparency in the tracking and monitoring of cancer research financing is essential to enable accountability and equity in resource allocation and to facilitate further future research in this area. We would encourage CRUK to be more open in providing data on funding.

In this study, we systematically analyse UK investment in cancer research and identify areas of relative neglect. Although the competitive application process used by most funders to allocate research grants ensure a portfolio of high quality, the absence of explicit resource allocation criteria could contribute towards inequalities in R\&D by disease burden. Funding agencies will have particular areas of focus, and UK funders may have considered the focus of international agencies in their own research strategies. As a result, international data is essential to complete the mapping of cancer research investment. Nevertheless, our findings will inform funders and contribute towards policy discussions that reduce inequities in the allocation of limited financial resources.

By demonstrating the relationship between disease burden and research funding, we enable the identification of potential investment gaps. However, it is not possible to fully equate gaps in funding with areas of neglect without consideration of other influences such as the feasibility of research, costs of technologies, infrastructure and skill requirements, political and social considerations and the accuracy of disease burden estimates.

There are several potential limitations to our study. We are dependent on the accuracy of original investment data as sourced from the funding bodies. Although checks were made on any obvious discrepancies or 
errors, interpretation of these original data may contain errors. We made no attempt to investigate the contribution of any indirect or estate costs. Currency conversions were averaged across each financial year and any intrayear fluctuations may not have been captured. Unless clearly documented, we were unable to assess how funding was distributed from lead institutions to collaborative partners. We considered individual awards, rather than number of studies.

Furthermore, assignment of disease categories and allocation of studies according to these categories is subjective, and there might be disagreements regarding certain inclusion criteria. As YLLs were not included in our analysis, we may underrepresent the disease burden of cancers that occur disproportionately in the young and which are associated with poor survival, notably cancers of the ovary, cervix and CNS. ${ }^{13}$ However, we would expect any additional information offered by YLL analysis to be predominantly captured by use of DALYs.

We could not openly access data of private sector research funding, nor were we able to obtain disaggregated award data from CRUK. While our analysis did demonstrate that CRUK funding (with some exceptions) broadly reflected the findings of our quantitative database, it is likely that substantial awards towards particular areas of research could skew results; for example, CRUK are particularly keen to fund clinical trials, an area typically not covered to such an extent by other public and philanthropic funders. In 2014/2015 CRUK invested $£ 394$ million into research or research-related activity, and we hypothesise that much of that would have met our inclusion criteria for this analysis. ${ }^{30}$ Disease burden measures are typically an estimate and are subject to the potential introduction of bias from missing or unobtainable data as well as from differences in classification and diagnosis.

Our report presents the latest investment data on cancer research awarded to UK institutions between 2000 and 2013. Cancers of the liver, thyroid, lung, upper GI tract and bladder as well as research towards radiotherapy and surgical techniques in particular may warrant increased rates of investment. We will make the entire database and associated figures available online (http://www.researchinvestment.org) to assist policymakers, funding organisations and researchers in the identification of investment gaps. We further encourage funding organisations to make their investment portfolios openly accessible to facilitate future research.

We hope that open funding data in this area can contribute to redressing the misalignments in investments for cancer research. Cancer research can improve the clinical course of disease and offer tangible improvements in health outcomes. ${ }^{23}$ Access to open data across all funders is essential, and transparency can assist policymakers and the scientific community in ensuring that limited resources are allocated appropriately and thus most effectively alleviate the extensive mortality and morbidity associated with cancer.
Author affiliations

${ }^{1}$ Epidemiology and Public Health, University College London, London, UK

${ }^{2}$ Faculty of Medicine, Global Health Research Institute, Institute for Life

Sciences, University of Southampton, Southampton, UK

${ }^{3}$ Medical Sciences Division, University of Oxford, Oxford, UK

${ }^{4}$ Harvard University, Cambridge, Massachusetts, USA

${ }^{5}$ Faculty of Medicine, Imperial College London, London, UK

${ }^{6}$ Department of Applied Health Research, UCL, London, UK

${ }^{7}$ Harvard T. H. Chan School of Public Health, Harvard University, Boston, Massachusetts, USA

Contributors MM and MGH are the guarantors of this study. MM, MGH, JRF and RA conceived and designed the study. MGH, CDZ, BJG and MAE-H obtained the data. MM and MGH conducted data formatting and statistical analysis. All authors helped interpret the findings. MM, MGH and CDZ wrote the first draft of the manuscript with input from RR, JRF and RA; all authors provided input to subsequent drafts. All authors had full access to all of the data in the study and take responsibility for its integrity and the accuracy of data analysis.

Funding This research received no specific grant from any funding agency in the public, commercial or not-for-profit sectors.

Competing interests None declared.

Provenance and peer review Not commissioned; externally peer reviewed.

Data sharing statement All data used are publicly available. Entire database and associated figures are permanently available with open access online (http://www.researchinvestment.org) to assist policymakers, funding organisations and researchers.

Open Access This is an Open Access article distributed in accordance with the Creative Commons Attribution Non Commercial (CC BY-NC 4.0) license, which permits others to distribute, remix, adapt, build upon this work noncommercially, and license their derivative works on different terms, provided the original work is properly cited and the use is non-commercial. See: http:// creativecommons.org/licenses/by-nc/4.0/

\section{REFERENCES}

1. Naghavi M, Wang $\mathrm{H}$, Lozano $\mathrm{R}$, et al. Global, regional, and national age-sex specific all-cause and cause-specific mortality for 240 causes of death, 1990-2013: a systematic analysis for the Global Burden of Disease Study 2013. Lancet 2015;385:117-71.

2. Jemal A, Bray F, Center MM, et al. Global cancer statistics: 2011. CA Cancer J Clin 2011;61:69-90.

3. Torre LA, Bray F, Siegel RL, et al. Global cancer statistics, 2012. CA a cancer $J$ Clin 2015;65:87-108.

4. Luengo-Fernandez R, Leal J, Gray A, et al. Economic burden of cancer across the European Union: a population-based cost analysis. Lancet Oncol 2013;14:1165-74.

5. Yabroff KR, Lund J, Kepka D, et al. Economic burden of cancer in the United States: estimates, projections, and future research. Cancer Epidemiol Biomarkers Prev 2011;20:2006-14.

6. Head MG, Fitchett JR, Cooke MK, et al. UK investments in global infectious disease research 1997-2010: a case study. Lancet Infect Dis 2013;13:55-64.

7. Head MG, Fitchett JR, Nageshwaran V, et al. Research investments in global health: a systematic analysis of UK infectious disease research funding and global health metrics, 1997-2013. EBioMedicine 2016;3:180-90.

8. Head MG, Fitchett JR, Derrick G, et al. Comparing research investment to United Kingdom institutions and published outputs for tuberculosis, HIV and malaria: a systematic analysis across 19972013. Health Res Policy Syst 2015;13:63.

9. Murray CJL, Barber RM, Foreman KJ, et al. Global, regional, and national disability-adjusted life years (DALYs) for 306 diseases and injuries and healthy life expectancy (HALE) for 188 countries, 19902013: quantifying the epidemiological transition. Lancet 2015;386:2145-91.

10. Vos T, Barber RM, Bell B, et al. Global, regional, and national incidence, prevalence, and years lived with disability for 301 acute and chronic diseases and injuries in 188 countries, 1990-2013: a systematic analysis for the Global Burden of Disease Study 2013. Lancet 2015;386:743-800.

11. Murray CJ, Vos T, Lozano R, et al. Disability-adjusted life years (DALYs) for 291 diseases and injuries in 21 regions, 1990-2010: a 
systematic analysis for the Global Burden of Disease Study 2010. Lancet 2012;380:2197-223.

12. Lozano R, Naghavi M, Foreman $\mathrm{K}$, et al. Global and regional mortality from 235 causes of death for 20 age groups in 1990 and 2010: a systematic analysis for the Global Burden of Disease Study 2010. Lancet 2012;380:2095-128.

13. Burnet NG, Jefferies SJ, Benson RJ, et al. Years of life lost (YLL) from cancer is an important measure of population burden-and should be considered when allocating research funds. $\mathrm{Br} \mathrm{J}$ Cancer 2005;92:241-5.

14. Carter AJR, Delarosa B, Hur H. An analysis of discrepancies between United Kingdom cancer research funding and societal burden and a comparison to previous and United States values. Heal Res Policy Syst 2015;13:62.

15. Carter AJR, Nguyen CN. A comparison of cancer burden and research spending reveals discrepancies in the distribution of research funding. BMC Public Health 2012;12:526.

16. Barton MB, Frommer M, Shafiq J. Role of radiotherapy in cancer control in low-income and middle-income countries. Lancet Oncol 2006;7:584-95. http://ac.els-cdn.com/S1470204506707598/1-s2. 0-S1470204506707598-main.pdf?_tid=41dac6b8-7fa0-11e3-a45c00000aabOf27\&acdnat=1389981382_3394f8c1d926c07e5acaad 4254556251

17. Barton MB, Jacob S, Shafiq J, et al. Estimating the demand for radiotherapy from the evidence: a review of changes from 2003 to 2012. Radiother Oncol 2014;112:140-4.

18. Sullivan R, Alatise OI, Anderson $\mathrm{BO}$, et al. Global cancer surgery: delivering safe, affordable, and timely cancer surgery. Lancet Oncol 2015;16:1193-224.

19. Gross CP, Anderson GF, Powe NR. The relation between funding by The National Institutes of Health and the burden of disease. N Engl J Med 1999;340:1881-7.

20. Catalá López F, Alvarez Martín EA, Gènova Maleras RG, et al Relationship between research funding in the Spanish national health system and the burden of disease. Rev Esp Salud Publica 2009;83:137-51.

21. Mitchell RJ, McClure RJ, Olivier J, et al. Rational allocation of Australia's research dollars: does the distribution of NHMRC funding by National Health Priority Area reflect actual disease burden? Med J Aust 2009;191:648-52.

22. Lamarre-Cliche M, Castilloux AM, LeLorier J. Association between the burden of disease and research funding by the Medical Research Council of Canada and The National Institutes of Health. A cross-sectional study. Clin Invest Med 2001;24:83-9.

23. Glover M, Buxton M, Guthrie S, et al. Estimating the returns to UK publicly funded cancer-related research in terms of the net value of improved health outcomes. BMC Med 2014;12:99.

24. Luengo-Fernandez R, Leal J, Gray A. UK research spend in 2008 and 2012: comparing stroke, cancer, coronary heart disease and dementia. BMJ Open 2015;5:e006648.

25. Sussex J, Feng Y, Mestre-Ferrandiz J, et al. Quantifying the economic impact of government and charity funding of medical research on private research and development funding in the United Kingdom. BMC Med 2016;14:32.

26. Teperek M. In conversation with Wellcome Trust and Cancer Research UK. Published Online First: 2016. https:// unlockingresearch.blog.lib.cam.ac.uk/?p=528

27. Teperek M. Charities' perspective on research data management and sharing. Published Online First: 2016. https://unlockingresearch. blog.lib.cam.ac.uk/? $\mathrm{p}=525$

28. Fitchett JRA, Sharara N, Head MG, et al. Transparency and availability of data for cancer research. Lancet 2016;388:866-7.

29. Davies J, Yudkin JS, Atun R. Liberating data: the crucial weapon in the fight against NCDs. Lancet Diabetes Endocrinol 2016;4:197-8.

30. CRUK. Annual report and accounts 2014/15. 2015. http://www. cancerresearchuk.org/sites/default/files/annual_report_and accounts_2014-15.pdf 